\section{Implementing Geo Citizen Science Solutions: Experiences from the citizenMorph Project}

GI_Forum 2020, Issue 1

Page: 3 - 14

Full Paper

Corresponding Author:

sabine.hennig@sbg.ac.at

DOI: 10.1553/giscience2020_01_s3

Sabine Hennig ${ }^{1}$, Lorena Abad ${ }^{1}$, Daniel Hölbling ${ }^{1}$ and Dirk Tiede ${ }^{1}$

${ }^{1}$ Sa Izburg University, Austria

\begin{abstract}
To exploit the potential of geo citizen science, tec hnologic al solutions are needed that are tailored to the requirements of citizens and scientists. To create suitable solutions, partic ipatory design is a valuable means. While information on techniques for requirementgathering in cooperation with future solution users exists, less knowledge is available regarding tools for creating solutions together with future solution users. One tool used in a professional setting is ESRI's Survey123 for Arc GIS. The suitability of Survey123 for Arc GIS to implement geo citizen science solutions was evaluated within the citizenMorph project. The experiences showed that by using Survey 123 for Arc GIS most requirements were met, but citizens faced a number of challenges using the citizenMorph solution developed.
\end{abstract}

\title{
Keywords:
}

contributory web maps, geomorphologic al phenomena, geo citizen science, landsc ape dynamics, participation, Survey123 for Arc GIS

\section{Introduction and research questions}

The rapid advance of Information and Communication Technologies (ICT) triggered a shift from traditional to online participation. The use of geospatial technologies - allowing, e.g., the public to contribute spatial information - has also received increasing attention. An example of making broad use of online participation, including geospatial technologies, is citizen science. Citizen science is the engagement of citizens in scientific processes with the aim of actively integrating them, their knowledge and commitment into scientific research and, thus, gaining new scientific knowledge. This can take different forms (Haklay 2013): (i) crowdsourcing projects (passive generation of data), (ii) contributory projects (citizens' active contributions of data based on their own observations), (iii) collaborative projects (actively contributing data and taking part in project design), and (iv) co-created projects (participating in project design and implementation). The integration of spatial data into citizen science is also called geo citizen science (Murray 2018). Contributory web maps can play an important role in geo citizen science because of their popularity among the public.

To fully exploit the existing potential of (geo) citizen science, technological solutions are needed that are tailored to the requirements of citizens and scientists and that take into account 
experiences gained in the field of participation (Hennig et al. 2019). However, citizens' demands, particularly with regard to spatial data products, often differ substantially from the requirements of experts and are less well known (Tsou \& Curran 2008).

To understand users, their resources and needs, and to consider these aspects when creating technological solutions, the active and direct participation of the future users in the development process (participatory design) is a valuable approach. It supports the development of solutions that deliver better user experience, increases the acceptance of the product in use, and ensures that the tool meets the requirements of the intended target group (Muller \& Druin 2012; Steen et al. 2007). To successfully use the participatory design approach, the techniques and tools used in the development process must support the intended involvement of future users. While information regarding requirement-specification techniques is available (e.g., related to user-centered design), information regarding tools used for solution implementation (particularly geospatial technologies) is lacking.

One tool used to deliver off-the-shelf solutions for spatial information collection is ESRI's Survey 123 for ArcGIS (hereinafter referred to as Survey 123). It is used mainly to support research in ecology, biology and the social sciences (Ahmed II \& Pradhan 2019), and less in areas such as geomorphology and landform dynamics. Although there are several benefits to using Survey 123 (e.g., easy and intuitive to learn and use, well documented, interoperability of various ESRI products), the question is how suitable Survey 123 is for the creation of geo citizen science solutions. How well can project-specific requirements (in terms of the research domain and the target group) be met by using Survey 123? The citizenMorph project, which aims at developing technological solutions for citizens to contribute (spatial) information on landforms, addresses these questions.

\section{The citizenMorph project}

The citizenMorph project (Observation and Reporting of Landscape Dynamics by Citizens; http://citizenmorph.sbg.ac.at) is an expansion of the research project MORPH (Mapping, Monitoring and Modelling the Spatio-Temporal Dynamics of Land Surface Morphology, http://morph.zgis.at). The project is funded by the Austrian Science Fund (FWF) as part of the Top Citizen Science (TCS) funding initiative, which aims to include citizen science components in ongoing FWF projects. The main MORPH project focuses on the development of novel methods addressing the spatial-temporal dynamics of surface morphology by integrating various optical and radar remote-sensing data for a study area in Iceland. In connection with this goal of the main project, there is (still) a high demand for data (including images) gathered directly in the field (e.g., recording actual events, landform characteristics or landscape changes). The field data can be used for 3D reconstruction of the surface using Structure from Motion (SfM) and dense image matching (DIM) techniques, for enriching and validating remote-sensing based mapping results, as well as for increasing their detail and information content. The joint availability of field and remote-sensing data is of importance for comprehensive analysis and helps to broaden knowledge about geomorphological landscape dynamics and the prevalence of particular landforms. 
Since field data cannot be delivered by scientists only (due, e.g., to time, budget and distance constraints), citizen science (i.e., citizens' data contributions) is beneficial in two ways: first, the contribution of field data and, second, citizens' input to the development of a technological solution that is tailored to their needs, which thus secures the contribution of extensive, highquality field data. The citizenMorph project addresses these issues by developing a pilot solution, in cooperation with citizens, that allows them to contribute field data on landforms regarding mass movements (e.g., rockfall, debris flow), volcanism (e.g., lava flow, lahar), glacial features (e.g., moraine, drumlins), and coastal processes (e.g., cliff erosion).

Although the main project's study area is limited to Iceland, the citizenMorph project is aimed at collecting data anywhere in the world, with the collaboration of local citizens and scientists. Consequently, not only is testing the citizenMorph solution in the MORPH study area in Iceland key, but testing it in other regions, taking into account different types of landform and landscape dynamics, is also important.

\section{Survey123 for ArcGIS}

Survey 123 for ArcGIS from ESRI was introduced in 2016. It is a simple, form-centric solution for creating, collecting, sharing and analysing so-called smart forms or surveys that allow collecting various types of information (including spatial data) using web or mobile devices (ESRI 2018). In general, a form is an online document that contains different types of questions, and text boxes in which to insert the required information. Multimedia (images, audio and video files) can usually be embedded to support the questions in various ways. Additionally, smart forms contain validation and logic, which means, for instance, that grouping of questions is possible and that people are only asked questions which apply to them (i.e., questions may appear or disappear depending on earlier responses).

The off-the-shelf smart forms created by Survey 123 - using either the online tool (Survey 123 web designer) or the desktop application (Survey123 Connect for ArCGIS) - are in line with these characteristics. There is the possibility of using different question types (closed questions: single- and multiple-choice questions, single-choice grid questions, rating and Likert-scale questions; open questions: adding text, number, date and time, and contributing images). Crucial is the GeoPoint question, which allows citizens to report on a location using their mobile device's GPS sensor, or to choose the location themselves on an interactive map. Question logic and grouping of questions can be used (ESRI 2017). In addition, to provide projectrelevant and further related information (e.g., to support and guide participants in how to complete the survey), single- and multi-line text boxes and notes can be added along with hints accompanying each question and form field. All these features can be leveraged using Survey 123 web designer, even more options are available using Survey 123 Connect for ArGGIS. For instance, repeats of questions to capture multiple versions of the same information can be implemented, and images and audio files can be added to the choices for single- and multiple-choice questions (ESRI 2016).

The comparatively simple structure of Survey 123 makes it an easy-to-use and intuitive tool to create off-the-shelf smart forms. Good support is available through the official ESRI websites, blogs and forums. In particular, creating and sharing surveys by using Survey 123 web designer is 
straightforward. It allows the design of surveys in a short time and without special ICT or GI/GIS expertise. Compared to Survey123 web designer, the use of Survey123 Connect for ArcGIS is technically more demanding.

Several options exist for distributing and using a Survey 123 smart form. The most common is the use of the Survey 123 field app, available for Android and iOS, which allows participants to download surveys and start collecting data. Another possibility is to share surveys as a web link (URL, QR Code) that can be opened and filled in through a web browser. Both possibilities provide different capabilities, which depend on either online or offline usage (Table 1).

The data captured and submitted by collaborators can be immediately accessed via the Survey 123 website, which includes various reporting and mapping possibilities. Due to the interoperability of ESRI products, the data collected are available for visualization and analysis in other ESRI products (e.g., ArcGIS Online, ArcGIS Pro). However, the use of ESRI products (including Survey 123) is not free of charge; it requires a licence. For participants, that does not matter: the Survey 123 smart forms can be completed without having an ESRI account.

Table 1: Selection of Survey123 smart form characteristics: Survey123 field app and browser-based option.

\begin{tabular}{|l|l|l|l|}
\hline & \multicolumn{2}{|l|}{ Survey123 field app } & Browser-based option \\
\hline Accessibility & $\begin{array}{l}\text { mobile application via Apple App Store } \\
\text { or Google Play Store plus adding the } \\
\text { survey }\end{array}$ & $\begin{array}{l}\text { open URL/ scan QR } \\
\text { Code; add to home } \\
\text { screen }\end{array}$ \\
\hline $\begin{array}{l}\text { Update } \\
\text { needs to be loaded on the mobile } \\
\text { device, but there is no option to } \\
\text { notify the user of a survey update } \\
\text { through the native application }\end{array}$ & $\begin{array}{l}\text { no problem using the } \\
\text { same }\end{array}$ \\
\hline Usage & online offline & online \\
\hline $\begin{array}{l}\text { Information } \\
\text { provision }\end{array}$ & question hints, multi-/ single-line text (expand/ collapse) \\
\hline $\begin{array}{l}\text { Access to URL, } \\
\text { multimedia }\end{array}$ & accessible not accessible & accessible \\
\hline $\begin{array}{l}\text { Style changes } \\
\text { (font, colour, } \\
\text { etc.) }\end{array}$ & $\begin{array}{l}\text { limited - only small font size in info } \\
\text { boxes }\end{array}$ & $\begin{array}{l}\text { font size and colour } \\
\text { can be adjusted }\end{array}$ \\
\hline $\begin{array}{l}\text { Use of audio } \\
\text { files }\end{array}$ & $\begin{array}{l}\text { limited control over audio playback } \\
\text { (e.g., no pausing the audio or fast- } \\
\text { forwarding) }\end{array}$ & $\begin{array}{l}\text { control over audio } \\
\text { playback possible }\end{array}$ \\
\hline $\begin{array}{l}\text { Use of images } \\
\text { (single-/ } \\
\text { multiple- choice } \\
\text { questions) }\end{array}$ & no zooming/ flipping, no external links & $\begin{array}{l}\text { provision via external } \\
\text { links that } \\
\text { zooming/ flipping }\end{array}$ \\
\hline $\begin{array}{l}\text { Basemaps } \\
\text { automatically } \\
\text { provided } \\
\text { basemaps) }\end{array}$ & $\begin{array}{l}\text { custom basemaps, } \\
\text { complex } \\
\text { provide on mobile } \\
\text { tevices }\end{array}$ & $\begin{array}{l}\text { automatically } \\
\text { provided } \\
\text { basemaps) }\end{array}$ \\
\hline
\end{tabular}




\begin{tabular}{|l|l|l|}
\hline $\begin{array}{l}\text { Map symbols on } \\
\text { Geopoint question }\end{array}$ & no customized ones \\
\hline $\begin{array}{l}\text { Ongoing } \\
\text { participation }\end{array}$ & $\begin{array}{l}\text { easy, asked at the end of the survey- } \\
\text { filling process }\end{array}$ & reloading web page \\
\hline
\end{tabular}

\section{Workflow, methods and tools}

Various approaches and methods were used in the development of the citizenMorph solution (Figure 1). First, the participatory design approach provided the general idea behind the development process. It allowed the direct, active involvement of target-group representatives in activities such as the specification of requirements, and the design, implementation and testing of the solution; the representatives of the target group were also included in decisionmaking (see, e.g., Baek et al. 2007). In addition, the stages in the development of the citizenMorph system were based on a prototyping process model (Kumar 2003): requirements are specified, prototypes are implemented and discussed in an iterative manner, and finally the final product is designed and implemented (Figure 1).

The citizen representatives ( 25 high school students, 14 undergraduate students, and eight older adults enrolled in continuing education) contributed to the various tasks, delivered prototypes, and to varying degrees were involved in decision-making. Different methods suitable for involving citizens (ICT, GI/GIS laypeople) were applied (Figure 1). The implementation of prototypes and the final system, in cooperation with citizen representatives, took place using Survey123 web design (Version 3.7), Survey123 Connect for ArrGIS (Version 3.3.51), and the content management system (CMS) WordPress (Version 5.2.5).

Prototyping process model

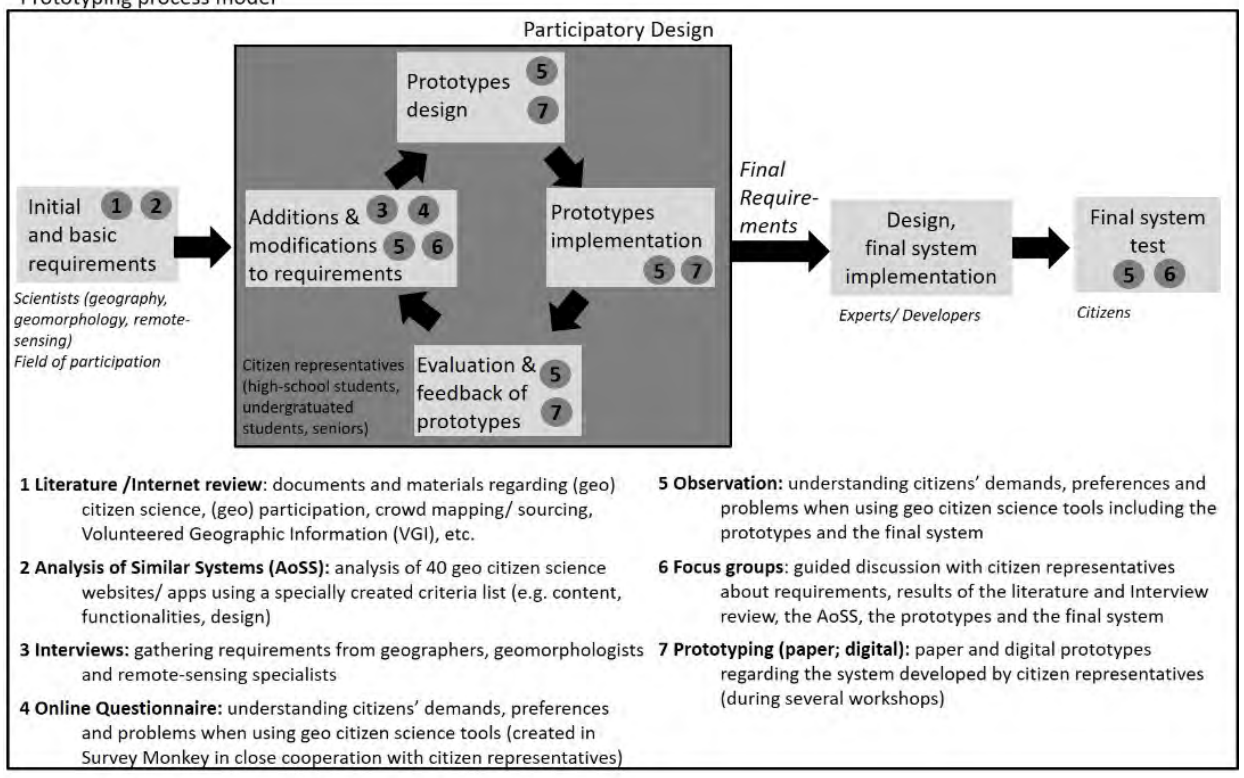

Figure 1: Workflow for the citizenMorph system development 
The final citizenMorph system was tested and evaluated on four occasions by citizen representatives and experts:

- Excursion to the Berchtesgaden National Park, Germany, and the Weißbach Nature Park, Austria (14 participants: high-school students, seniors, experts; 11 July 2019)

- Excursion with workshop in Höfn, Iceland (15 participants: high-school students and experts; 5 September 2019)

- Workshop at Lomonosov State University Moscow, Russia (8 undergraduate students; 19 September 2019)

- Workshop (international GIS day) at Salzburg University (58 high-school and undergraduate students; 13 November 2019)

Observing those testing the solution (while they were using the citizenMorph system to complete the survey) and carrying out focus groups (after they had used the citizenMorph system to complete the survey) gave an insight into problems that citizens face using the citizenMorph solution. The findings from the observation and focus groups were coded and grouped under the categories 'survey distribution and installation', 'registration and login', 'design and usability', 'data contribution' and 'help and support'.

\section{$5 \quad$ Requirements and system structure}

The different stakeholders (experts: geomorphologists, geographers, remote sensing specialists; citizens) have different requirements of the citizenMorph technological solution. These include knowledge regarding participating in the research area, people's motivations, their digital skills, and the importance of building and maintaining a project community (Hennig et al. 2019; van Dijk 2012).

To meet the requirements specified (Table 2), the implementation of a system that only allows information to be contributed is not enough. As stressed by Hennig \& Begiu (2011) and Murgante et al. (2011), additional components are required, notably information for volunteers about the project more generally, the data collection and reporting processes, security and safety issues, and feedback. The system must also allow social-networking possibilities (i.e. communication and interaction options) and facilitate building and maintaining a project community by participants. All these components are present in the citizenMorph system.

Table 2: Selected citizenMorph system requirements

\begin{tabular}{|l|c|}
\hline & Requirements/ needs/ preferences \\
\hline $\begin{array}{l}\text { General } \\
\text { usability/ } \\
\text { design }\end{array}$ & $\begin{array}{l}\text { Easy to access and use; as self-explanatory as possible; } \\
\text { attractive design }\end{array}$ \\
& $\begin{array}{l}\text { Well-written and understandable text; short, dense and well- } \\
\text { structured content }\end{array}$ \\
& $\begin{array}{l}\text { Online and offline uses possible for a variety of mobile devices } \\
\text { Use of different media to provide information, support and help }\end{array}$
\end{tabular}




\begin{tabular}{|c|c|}
\hline & $\begin{array}{l}\text { - Customizable text size (readability); possibility to enlarge } \\
\text { and flip images }\end{array}$ \\
\hline $\begin{array}{l}\text { Help/ } \\
\text { support/ } \\
\text { guidance }\end{array}$ & $\begin{array}{l}\text { - Information about related domains; project baseline information } \\
\text { - Information about how to collect and report data, including } \\
\text { support with spatial literacy skills } \\
\text { - Information about how to take images (single image, image } \\
\text { series) } \\
\text { - Information about safety/ security issues (being on-site, } \\
\text { intellectual property rights, personal data) }\end{array}$ \\
\hline $\begin{array}{l}\text { Data } \\
\text { contributio } \\
\text { n }\end{array}$ & $\begin{array}{l}\text { - Intuitive use; comfortable, quick and easy input (only relevant } \\
\text { questions) } \\
\text { - Support in identifying landforms: guiding users by } \\
\text { questionnaire logic and information } \\
\text { - Possibility to add a single image of the landform as well as a } \\
\text { series of overlapping images (e.g. prerequisite for SfM-based } \\
\text { 3D reconstruction) } \\
\text { - Possibility to contribute data on-site and/ or at home using } \\
\text { different devices } \\
\text { - Possibility to edit data entries after submission }\end{array}$ \\
\hline $\begin{array}{l}\text { Community/ } \\
\text { contact }\end{array}$ & $\begin{array}{l}\text { - Directly addressing participants in the context of the project } \\
\text { - Direct feedback to participants in the context of the project } \\
\text { (optional) } \\
\text { - Opportunities for contact and exchange with others (citizens, } \\
\text { project team) } \\
\text { - Opportunities to gain insight into the project community } \\
\text { - Provision and collection of a very limited amount of personal } \\
\text { data; not mandatory }\end{array}$ \\
\hline
\end{tabular}

\section{Survey123 smart form implementation}

Even though citizen representatives need to be able to use the survey both online and offline, of the two common ways to share a survey (field app; browser-based variant), the browserbased variant was chosen (https://arcg.is/15WPKv0). By using many of the capabilities provided by Survey123 (online and desktop tool), it was possible to meet most of the requirements (Figure 2 ).

Different kinds of information are provided in the Survey123 smart form: welcoming, project baseline information, support and guidance for collecting and reporting data, data protection information, and thanks and feedback to volunteers. Question hints and multi-line text boxes (possibility to expand/ collapse) allow the delivery of various levels of information to participants (for newcomers: more information; for experienced users: less/ no information). In the case of citizens' strong interest in selected topics, text boxes and question hints include links to additional information available on the citizenMorph website. Providing different levels of information to participants has various benefits: it allows the provision of survey-relevant descriptions and guidelines only when needed; it prevents the demotivation of volunteers while 
they are familiarizing themselves with and completing the survey, since they are not overwhelmed by unwanted information.

Since users often refuse to read (lengthy) text (Hennig \& Vogler 2016), audio files were created in addition to the written text. The audio files were produced by citizen representatives with the aims of attracting and motivating citizen participants to complete the survey and, at the same time, of giving the most relevant information (necessary survey-filling instructions). Having citizen representatives create the audio files, only terms that the citizens themselves are familiar with are used, and it is more likely that the content will be neither too long nor too technical.

http://citizenmorph.sbg.ac.at/

\begin{tabular}{|c|c|}
\hline $\begin{array}{c}\text { Extended internet presence } \\
\text { citizenMorph website (CMS Wordpress) }\end{array}$ & $\begin{array}{c}\text { Spatial information contribution } \\
\text { citizenMorph smart form (Survey123 for ArcGIS) } \\
\text { Welcoming (image i.e. project logo) }\end{array}$ \\
\hline $\begin{array}{l}\text { Comprehensive Information } \\
\text { (web pages incl. links to other websites) } \\
\text { Project (baseline information) } \\
\text { Data collection/ reporting } \\
\text { Security/ safety issues }\end{array}$ & $\begin{array}{c}\text { Brief information * } \\
\text { Project, background, domains, contact, ... } \\
\text { General security/ safety issues taking part and on-site } \\
\text { (incl. personal data protection) }\end{array}$ \\
\hline $\begin{array}{c}\text { Feedback } \\
\text { Project progress, results } \\
\text { (timeline, image gallery, publications) } \\
\text { Participants' data contributions } \\
\text { (e.g. ArcGIS online web map) }\end{array}$ & $\begin{array}{l}\text { Data Contribution with Instructions * } \\
\text { Username and email (open question) ** } \\
\text { Landform identification (single-choice question with logic, } \\
\text { link to image, i.e. "information cards" for each choice) } \\
\text { Landform single image (image upload) ** } \\
\text { Landform image series (repeated image upload) ** }\end{array}$ \\
\hline $\begin{array}{c}\text { Social networking } \\
\text { To build/ maintain a project } \\
\text { community } \\
\text { (Web } 2.0 \text { tools, social networking services } \\
\text { SNS) }\end{array}$ & $\begin{array}{l}\text { Landform additional remarks (open question) } * * \\
\text { Consent to data use (single-choice question) } \\
\text { Thanks and feedback * } \\
\text { (link to ArcGIS online web map) }\end{array}$ \\
\hline
\end{tabular}

* to read: multiline text, question label, question hint (expand/collapse), links to citizenMorph website; to listen: audio files

** optional

Figure 2: Structure and components of the citizenMorph system and its implementation using Survey 123 web design and Survey 123 Connect for Arc GIS

The question types used in the citizenMorph survey include: (i) open questions to be answered optionally (e.g. participant's username and email; additional information about the landform under investigation); (ii) single-choice questions (select the type of landform; participant's consent on using the data contributed); (iii) the possibility of adding images (landform single image; landform image series using the repeat question option); and (iv) a GeoPoint question to report the landform location.

To guide and support citizens in the identification of landforms, question logic is used. Thus, a subsequent question (e.g., about landform type/ category) will depend on the answer to an earlier question. For example, if a participant selects the landform category 'glacier', a 
subsequent question will display related landforms as options for selection (moraine, rock glacier, etc.). In addition, information cards (jpg image presenting the name of the individual landform type/ category, a brief definition, explanatory images) were created to support participants in identifying landforms correctly. It is possible to add images to the answers to single- and multiple-choice questions, but the opened images cannot be zoomed or flipped. This is not in line with user needs for enlarging text and images. Thus, information cards were made accessible through links provided in the corresponding question hints. When opened in a browser, they can be zoomed and flipped.

\section{Survey123 smart form evaluation}

During the test events (focus groups), 80 statements relevant to Survey 123 usage were selected and summarized, quoting the most common statements per category (survey distribution \& installation: $10 \%$; registration \& login: $5 \%$; design \& usability: $21 \%$; data contribution: $35 \%$; help \& support: $29 \%$ ). Together with the findings from observing the testers, these issues are described further in the following sections.

\section{a) Survey distribution and installation}

Even though the testers had no problem in making the browser-based survey available on their mobile device, they suggested making a 'typical app' available. From their perspective, the survey would be easier to install, and apps are the standard way of distributing (mobile) web applications today. Using the Survey 123 field app does not meet testers' demands either, since it requires several steps: download the app from a mobile application store, install it, and add the survey of interest to the app. For use offline, an additional step is loading custom basemaps. For citizens, this is a complicated task that might discourage them from taking part in the survey. However, a major disadvantage of using the browser-based variant is that it is impossible to fill out the survey in remote areas where mobile network connectivity is poor or unavailable. In this case, participants have to wait for an internet connection to fill out the form with images taken earlier, and need to map the landform location from memory or by using recorded coordinates.

\section{b) Registration and login}

Even though the use of ESRI products usually requires an account, no registration and login are needed to complete a Survey 123 smart form. Because Survey 123 does not offer the option of participant registration, community building is not possible. The testers discussed the topic of registration and login. Filling out the survey without registration and the possibility of submitting data anonymously were considered positive, simplifying and accelerating the contribution process, and leading to fewer data privacy concerns. However, some testers mentioned that having a registration option would enhance community building and increase data quality. In this context, Jay et al. (2016) found that not having a registration step increases the number of contributors to citizen science projects by more than $60 \%$, but offering the option to create an account, without making it a requirement, maximizes the contribution rates. To address this issue (i.e., support community building), the citizenMorph system includes social-networking activities (i.e., communication and interaction options). Further, asking participants for username and email (which are optional) makes it possible to contact those 
who supply these details and give personal feedback. It also allows for the delivery of an ArcGIS Online web map showing the individual participant's data input.

\section{c) Design and usability}

Using Survey 123, developers work on a template that is provided. This gives little leeway for the design and layout of surveys to be modified (e.g., using corporate design, customized map symbols). Thus, it is not surprising that a recurrent remark of the testers was that the design of the citizenMorph survey was not attractive enough. Several ideas for improving its appearance and design were suggested. Examples are a clear typeface, effective use of images, and the position of buttons, links and arrows.

\section{d) Data contribution}

In a broad sense, the testers found the survey intuitive and had no major difficulties answering the questions. They only faced problems when capturing image series and navigating through the GeoPoint question. To submit a single image, the process is straightforward (the user is prompted either to use the built-in camera on a mobile device or to access its gallery to find an image). However, the process of submitting image series is described by testers as tedious and annoying. There is no possibility in Survey 123 of taking several images or of selecting them from the gallery in a single step. Instead (using the repeat question option), participants need to add each image separately, which requires them to actively add a new field in the survey to upload each new image. In addition, how to map a feature (GeoPoint question) was not always clear to the testers. Panning and zooming in the map manually to localize oneself and/or the landform of interest were considered difficult and confusing. Using the get-my-location functionality (based on the mobile device's GPS sensor) was not always evident; feedback here was negative. For some testers, typing their approximate address was a workaround when trying to locate themselves.

\section{e) Help and support}

Even though citizens need at least some basic information to start contributing, the testing revealed that most volunteers did not read the information available to guide them through the form-filling process, although this is vitally important. Instead, they attempted to complete the survey directly. Reasons for this are people's general dislike of reading text online and the fact that reading onscreen in an outdoor setting is often difficult (e.g., because of light conditions). In this regard, the audio files proved to be more useful and were mostly positively remarked on by the testers.

\section{Conclusion and outlook}

Survey 123 is a usable tool for cooperating with citizens in the context of participatory design. To meet all requirements of citizens, scientists and the participation domain in general, workarounds (e.g., use of images accompanying question choices) and compromises (e.g., a trade-off between online and offline use associated with different challenges) are required in some cases. In general, using Survey 123 web designer and Survey 123 Connect for ArGGIS to create off-the-shelf surveys is in line with off-the-shelf online (map-based) questionnaires: there are few possibilities regarding design and usability, and little focus on community building. Nevertheless, citizen science requires these features since they help encourage people to take 
part in initiatives. This underlines the importance of the multi-component nature of the citizenMorph system.

Another possibility that allows custom applications to be built is ESRI's AppStudio (incl. QT Creator). Nevertheless, the use of this tool is more demanding. For the citizenMorph project, this was not an option (because of limited budget, and citizen involvement in the solution development process). However, ESRI is constantly enhancing its products, fixing bugs, and adding new functionalities with each release. The community of developers who use these tools are able to present their concerns and get support. It is therefore expected that some of the issues we have mentioned will be improved for future releases of Survey 123.

\section{Acknowledgments}

The Top Citizen Science (TCS) project citizenMorph (FWF-TCS 47), and the main project MORPH (FWF-P29461-N29) are funded by Austrian Science Fund (FWF).

\section{References}

Ahmed II, J.B. \& Pradhan, B. (2019). Spatial assessment of termites' interaction with groundwater potential conditioning parameters in Keffi, Nigeria. Journal of Hydrology, 578, 124012.

Baek, E.-O., Cagiltayik, K., Boling, E. \& Frick, T. (2007). User-Centered Design and Development. In Handbook of Research on Educational Communications and Technology, ed. J. M. Spector, M. D. Merrill, J. J. van Merrienboer, \& M. F. Driscoll, (pp. 659-670). New York: Routledge Chapman \& Hall.

ESRI (2016). Media. Retrieved January 15, 2020, from https://doc.arcgis.com/de/survey123/desktop/create-surveys/xlsformmedia.htm.

ESRI (2017). XLSForm essentials. Retrieved January 15, 2020, from https://doc.arcgis.com/en/Survey123/desktop/create-surveys/xlsformessentials.htm.

ESRI (2018). Survey123 for ArcGIS starten. Retrieved January 15, 2020, from https://www.esri.com/en-us/arcgis/products/Survey123/overview.

Haklay, M. (2013). Citizen Science and Volunteered Geographic Information - overview and typology of participation. In Crowdsourcing Geographic Knowledge: Volunteered Geographic Information (VGI) in Theory and Practice, ed. D. Z. Sui, S. Elwood \& M.F. Goodchild, (pp. 105-122). Berlin: Springer.

Hennig, S. \& Belgiu, M. (2011). User-centric SDI: Addressing User Requirements in Third-Generation SDI - The Example of Nature-SDIplus. Perspective, (pp. 30-42).

Hennig, S.; Hölbling, D.; Ferber, N. \& Tiede, D. (2019): Rahmenkonzept und Komponenten für Citizen Science Projekte. Das Projekt citizenMorph. AGIT - Journal (5).

Hennig, S. \& Voger, R. (2016). User-centred map applications through participatory design: Experiences gained during the "YouthMap 5020" project. The Cartographic Journal, 53(3), (pp. 213-229).

Jay, C., Dunne, R., Gelsthorpe, D., \& Vigo, M. (2016). To sign up, or not to sign up? Maximizing citizen science contribution rates through optional registration. Proceedings of the 34th Annual ACM Conference on Human Factors in Computing Systems (CHI'16), (pp. 1827-1832).

Kumar S. (2003). What is Prototype model- advantages, disadvantages and when to use it? Retrieved January 15, 2020, from http://tryqa.com/what-is-prototype-model-advantages-disadvantages-andwhen-to-use-it/.

Muller, M. J., \& Druin, A. (2012). Participatory design. The third space in HCI. In The buman-computer interaction handbook, ed. J. Jacko, (pp. 1051-68). Hillsdale Erlbaum. 


\section{Hennig et al}

Murray, T. (2018): Tracking ecosystem change through citizen science. Retrieved Dec 25, 2019, from https://www.biodiversityireland.ie/wordpress/wpcontent/uploads/2018_10_18_TrackCitSci_TMurray.pdf.

Murgante, B., Tilio, L., Lanza, V. \& Scorza, F. (2011). Using participative GIS and e-tools for involving citizens of Marmo Platano-Melandro area in European programming activities. Journal of Balkan and Near Eastern Studies, 13(1), (pp. 97-115).

Steen, M., L. Kuijt-Evers, \& Klok. J. (2007). Early user involvement in research and design projectsA review of methods and practices. 23rd EGOS Colloquium, Vienna, Austria.

Tsou, M.-H. \& Curran, J. M. (2008). 'User-centered design approaches for web mapping applications: a case study with USGS hydrological data in the United States', in International Perspectives on Maps and the Internet. Lecture Notes in Geoinformation and Cartography, ed. M.P. Peterson, (pp. 301-321), Berlin: Springer.

van Dijk, J. (2012). The Evolution of the Digital Divide - The Digital Divide Turns to Inequality of Skills and Usage. Digital enlightenment yearbook 2012, ed. J. Bus et al., (pp. 57-75), Amsterdam: IOS Press. 